\title{
Pregnancy History and Associated Factors Among Hawassa University Regular Undergraduate Female Students, Southern Ethiopia
}

\author{
Yohannes Fikadu Geda ${ }^{1,}$, , Melese Siyoum Desta ${ }^{2}$, Walellign Animut Tirfie ${ }^{3}$ \\ ${ }^{1}$ Department of Midwifery, Wolkite University, Wolkite, Ethiopia \\ ${ }^{2}$ Department of Midwifery, Hawassa University, Hawassa, Ethiopia \\ ${ }^{3}$ Department of Midwifery, Wolaita Sodo University, Sodo, Ethiopia \\ Email address: \\ nechsar@gmail.com (Y.F. Geda), melesesiyoum755@gmail.com (M. S. Desta), endua2020@gmail.com (W. A. Tirfie) \\ ${ }^{*}$ Corresponding author
}

\section{To cite this article:}

Yohannes Fikadu Geda, Melese Siyoum Desta, Walellign Animut Tirfie. Pregnancy History and Associated Factors Among Hawassa University Regular Undergraduate Female Students, Southern Ethiopia. American Journal of Laboratory Medicine.

Vol. 5, No. 3, 2020, pp. 76-82. doi: 10.11648/j.ajlm.20200503.13

Received: May 19, 2020; Accepted: June 22, 2020; Published: July 30, 2020

\begin{abstract}
Introduction: Global incidence of pregnancies among University students is increasing; and challenging in Universities of Ethiopia. There are a few studies on pregnancy experiences among university students in Ethiopia. The finding will be used by policy makers, additive of the existing knowledge and as a reference for future researchers. Objective: To assess magnitude of pregnancy experiences and associated factors among Hawassa University regular female students from May 1-15, 2019. Methods: Institution based cross-sectional study was conducted from May 1-15, 2019 and 741 participants were selected using multistage sampling method from Hawassa University regular undergraduate female students. EPidata for entry and SPSS for analysis were used. Variables with $\mathrm{p}<0.25$ on bivariate were used for multivariable analysis and $\mathrm{p}<0.05$ were considered significant. Result: Magnitude of pregnancies experience among Hawassa University regular undergraduate female students was 98 (13.2\%) (95\% CI: 10.8, 15.7). Collage of Agriculture 3.76 (AOR=3.76, 95\% CI: 1.66, 8.50), Social Science and Humanity 2.63 (AOR=2.63, 95\% CI: 1.02, 6.81), and Natural and Computational science 3.41 (AOR=3.41, 95\% CI: $1.54,7.54)$ times more likely to have pregnancy compared to college of Medicine and Health sciences. Married respondents were $2.39(\mathrm{AOR}=2.39,95 \% \mathrm{CI}$ : $1.54,7.54)$ times more likely to have pregnancy compared to respondents who were not married. Respondents source of income was parent were $47 \%$ (AOR $=0.53,95 \% \mathrm{CI}$ : $0.29,0.96$ ) less likely to have pregnancy compared to respondents whose source of income were partner. Respondents who have history of using contraceptive were $75 \%$ (AOR $=0.25,95 \% \mathrm{CI}$ : $0.14,0.44)$ less likely to have pregnancy. Conclusion: Magnitude of pregnancy experience was high among regular undergraduate female students of Hawassa University compared to other studies. Being non health colleges, married status, partner as a source of income and not having contraceptive usage history were statistically significant factors to have pregnancy. Non health colleges' needs to be evaluated about their SRH information flow by the university.
\end{abstract}

Keywords: Student, Pregnancy, University, Hawassa, 2020

\section{Introduction}

Global incidence of pregnancies among University students is increasing [1]. It is shown that out of 210 Million pregnancies occurring globally, nearly 80 million of them were unintended each year [2]. Recently, unintended pregnancy in Africa was reported to be 57 per 1000 female university students [3, 4]. In Sub-Saharan Africa 14 million unintended pregnancies occur every year, with almost half occurring among women aged 15-24 years [3]. In which $17 \%$ pregnancies were mistimed, and $8 \%$ were unwanted [5]. Around 101 unwanted pregnancies occurred per 1,000 women aged $15-44$, and $42 \%$ of all pregnancies were 
unintended [6].

The major reason for it is gap on accessing and practicing contraceptive [7, 8]. In Africa there is a high incidence of risky sexual behaviors among university Students [9]. Reproductive health-related knowledge gaps among sexually active University female student is an important cause of unintended pregnancy [10-13]. The outcome of unintended pregnancies is unsafe abortions (3); it is a global social and health burdens [2, $3,14]$. Death due to risks related with procedure of unsafe abortion is common [2]. Many of these abortions take place in legally restrictive settings [13, 15-17]. In Ethiopian students having unintended pregnancy is about 32.4\% [18]; more likely ends with abortion complications [19].

In Ethiopia education regarding family planning service and supply points helped to decrease the level of unintended pregnancy $[12,20]$; and the country also has an old population policy developed in 1993, which adopted the principle that every pregnancy should be wanted [2] Unintended pregnancy prevention practice is very low because young unmarried women have little access to information or advice about contraception [21]; access to contraceptive methods including emergency contraceptives can prevent unintended pregnancy [22].

Despite health education efforts, University female students are still faced with major preventable health problems [23]. The researches available from the student population in Ethiopia suggest that an unintended pregnancy is prevalent in Ethiopian universities [24, 25]. Unintended pregnancy is very critical challenge especially for students, but it is under reported due to the fact that the legal, social and cultural norms are not open to discussing the sensitive issue of unintended pregnancies followed by abortion [18]. Even though there is widespread availability of highly effective methods of contraception unintended pregnancy and induced abortion are still frequent and worrisome in Universities of Ethiopia [26].

Magnitude of pregnancy experience among University students as well as the factors associated with it at the community level is very crucial. There for this study would provide reference for the development of reproductive health policies, services to better address the sexual health needs, burden of unintended pregnancies and related complications among female students. It would be additives of the existing knowledge and can be used by public health providers as a reference. Since there were few studies on experience of pregnancies among Universities in Ethiopia the finding will also be used as a baseline for future researchers.

\section{Methods and Materials}

The study was conducted in Hawassa University (HU) located in Hawassa City. Hawassa is the capital city of southern nation's nationality peoples region (SNNPR) located at $275 \mathrm{~km}$ south to Addis Ababa, the capital city of Ethiopia. Currently, Hawassa University has seven functional campuses within this campuses, HU operates 8 Colleges and 1 Institute (Institute of Technology (IOT). Currently HU runs
81 Undergraduate degree programmes, 108 Masters and 16 $\mathrm{PhD}$ programmes in its, and 41 Schools and Departments. The student population as of March 2018 is 48,558 of which $28.86 \%$ are female [27].

Institutional based crossectional study was conducted from May 1-15, 2019. All undergraduate regular female students of Hawassa University were the source population of this study. All undergraduate regular female students of Hawassa University who fulfilled the eligibility criteria were the study population.

The required sample size was calculated using single population proportion formula and with an assumption of $95 \%$ confidence interval, $5 \%$ margin of error, a proportion of $32.4 \%$ from study done at Medawalabu University, Ethiopia on unwanted pregnancy (18). Which makes a sample size of 673; Adding 15\% contingency to account for non-response rate yielded a final sample size of 774 .

Stratified multistage sampling technique was used, and the procedure was as follows. Colleges were divided in to two practical strata as health and non-health colleges. Simple random sampling method was applied to select three nonhealth colleges, and sample size was allocated to the stratified colleges proportional to their size. Next three departments from each non health and health colleges have been included and then class years are stratified as first, second, third, fourth and above. The total sample size were again allocated to each class year proportional to their size, finally 774 students were selected by Simple Random Sampling (SRS) technique using identified females ID accessed from each collage registrar.

Pregnancy experience during life in university was dependent variable, and Socio demographic (Age, Marital status, Income, place of permanent residence, class year, partner occupation, partner education), Contraceptive related (heard about contraceptive, source information, type of contraceptive known, contraceptive experience, purpose of used contraceptive, type of contraceptive used), Pregnancy related histories (history of unwanted pregnancy, history of spontaneous abortion, history of induced abortion, place of termination, terminated by, materials used to terminate, reason of termination), Personal behaviors and experiences (history of intercourse, discuss about sexual and reproductive health issues, peer influence, drink alcohol, history of violence, take SRH course) were independent variables.

The data were collected by self-administered pretested questionnaires. Twelve data collectors and two supervisors were recruited. Moreover, practical exercises have been done by data collectors during training with the principal investigator how to introduce mentioned issues. Data collection was done by arriving at the end of the scheduled time based on the block number, lecture room number and time to collect data was arranged by communicating with department head and instructor who own each class during data collection time.

For all respondnents purpose of the study, confidentiality and the need for providing honest answers was clarified orally. They have signed written informed consent if they 
were above 18 other wise the consent was signed by their parents or legal gurdians. After necessary introduction was made the students have had informed how they were selected. Female students who were not included in the study and all male students were ordered to leave the class. In addition to specific instructions on the questionnaire, participants were given clear oral guidance on filling out the questionnaire.

Sitting arrangement was rearranged to make the process confidential and then questioners were distributed in the same time for all students in the same college and they have given similar time to finalize. They also ensured complete privacy during completing the questionnaire. Supervision of the data collection process was done by supervisors along with the principal investigator.

The questionnaire was prepared in English language and translated to Amharic language, and translated back to English for consistency. Training was given to data facilitators who are masters students and the supervisors before the actual data collectionon on how to approach and select the study participants, on the objective of the study and the content of the questionnaire. To check the clarity, consistency, skipping pattern and order of questions, questionnaire was pre-tested. After pretest, questions were revised, edited, and those found to be unclear were modified.

Data was checked manually for completeness. Then the data were cleaned and stored for consistency after entered in to Epi Data version 3.1 software. For further analysis the data were exported to statistical package for social sciences version 24.0 software. Descriptive statistics were carried out. Bivariate and multivariate analysis was used to see the effect of independent variable over unintended pregnancy. Variables which were significant on bivariate analysis at p-value less than 0.25 and biologically pausible were taken to multivariate analysis. The fitness of model was checked by Hosmer and Lemeshow test. In multivariate analysis P- value of less than 0.05 and $95 \%$ confidence level was used as a cut of point for presence of association. Finally, results were compiled and presented using tables, graphs, charts and texts.

\section{Result}

\subsection{Socio-demographic Characteristics of Respondents}

A total of 741 female students participated in this study out of 774 selected samples. Twelve filled questionnaires were discarded due to incompleteness resulting in a response rate of $95.74 \%$. Age of the study participants ranged from 18 to 27 years with a mean age of $20.94 \pm 1.79$, and the age groups 20-24 constituted $81.2 \%$. Among the 741 respondents, more than one-third $290(39.1 \%)$ were from collage of natural and computational science (table 1).

Respondents from year one accounts 234 (31.6\%), year two 241 (32.5\%), year three $237(32 \%)$ and year four 29 $(3.9 \%)$ were participated in this study. From this 105 (14.2\%) were married and $351(47.4 \%)$ have partner from both in university and out of university (table 1).
Table 1. Socio-demographic characteristics of pregnancy experience among Hawassa University regular female students, Hawassa, June 2019- (N=741).

\begin{tabular}{|c|c|c|}
\hline & Number & Percent \\
\hline \multicolumn{3}{|l|}{ Age } \\
\hline $15-19$ & 109 & 14.7 \\
\hline $20-24$ & 602 & 81.2 \\
\hline $25-29$ & 30 & 4.0 \\
\hline \multicolumn{3}{|l|}{ Collages } \\
\hline Natural and computational science & 290 & 39.1 \\
\hline Agriculture & 171 & 23.1 \\
\hline Social science $\&$ humanity & 147 & 19.8 \\
\hline Medicine and health science & 133 & 17.9 \\
\hline \multicolumn{3}{|l|}{ Year of study } \\
\hline Year one & 234 & 31.6 \\
\hline Year two & 241 & 32.5 \\
\hline Year three & 237 & 32 \\
\hline Year four & 29 & 3.9 \\
\hline \multicolumn{3}{|l|}{ Marital status } \\
\hline Not married & 636 & 85.8 \\
\hline Married & 105 & 14.2 \\
\hline \multicolumn{3}{|l|}{ Have partner $(\mathrm{N}=636)$} \\
\hline Yes & 351 & 55.19 \\
\hline No & 285 & 44.81 \\
\hline \multicolumn{3}{|l|}{ Place of permanent residence } \\
\hline Urban & 533 & 71.9 \\
\hline Rural & 208 & 28.1 \\
\hline \multicolumn{3}{|l|}{ Source of money } \\
\hline From parents & 613 & 82.7 \\
\hline From partner & 113 & 15.2 \\
\hline Other** & 15 & 2.02 \\
\hline
\end{tabular}

Other*: for occupation was working in family business

Other**: for source of money includes sisters, brothers and uncles.

\subsection{Personal Behavior and Experiences of Respondents}

About one third of the total respondents 249 (33.6\%) experience sexual intercourse, and mean age at first intercourse was $18.26 \pm 3.56$. Their reason of initiating sexual intercourse was by their own desire for more than two third 174 (70\%) of the respondents and who are pushed were by their partner 31 (12.45) from those who already start intercourse.

From the total respondents 483 (65.2) have had discuss about sexual reproductive health issues; their choice to discuss for majority of the respondents 354 (47.8) were peers. From the respondents 523 (70.6) of the respondents have taken the course sexual and reproductive health.

Almost all $710(95.8 \%)$ of the respondents were heard about prevention mechanisms of unintended pregnancy. Their source of information for more than half 412 (55.6\%) of the respondents was school. Condom was the most 524 (70.7) known contraceptive method by the respondents.

More than two third of the respondents 544 (73.4\%) have never use contraceptive. For the rest of the respondent their reason $122(15.1 \%)$ to use contraceptive was because they are students (figure 1).

From the total of 741 respondents magnitude of unintended pregnancy was 98 (13.2\%) (95\% CI: 10.8, 15.7) and magnitude of unintended pregnancy among those who experience intercourse was 239 (39.36\%) (figure 2). This means that all students who have pregnancy history were unintended. 


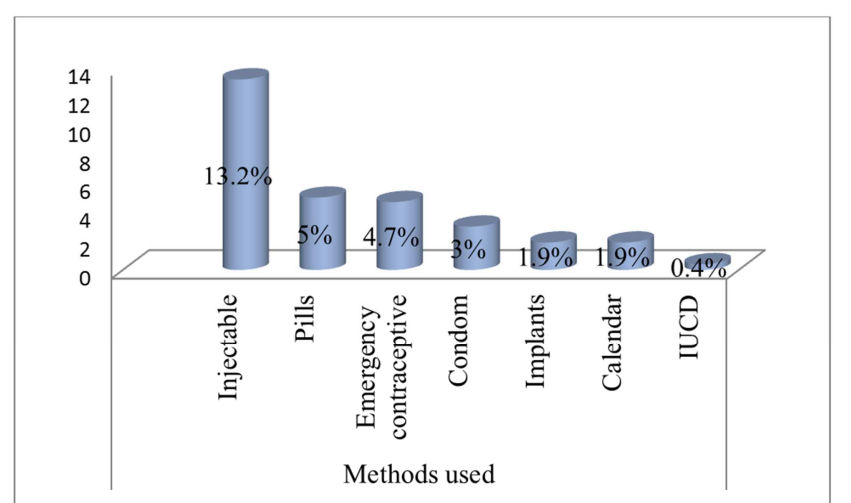

Figure 1. Contraceptive methods used by the respondents of pregnancy experience among Hawassa University regular female students, Hawassa, June 2019-(N=197).

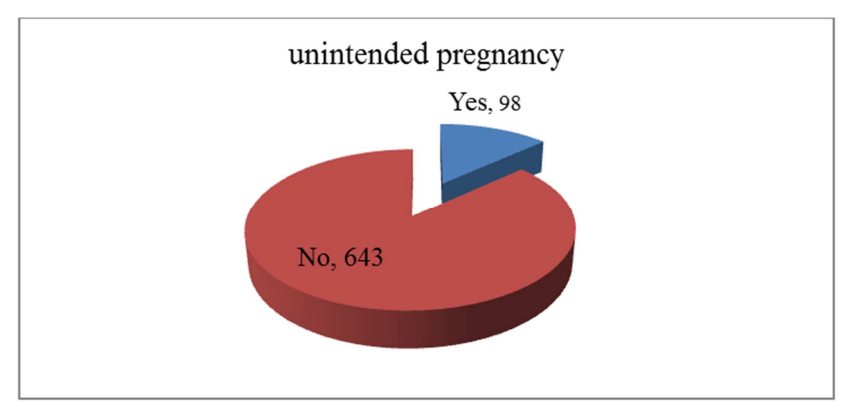

Figure 2. Magnitude of unintended pregnancy of pregnancy experience among Hawassa University regular female students, Hawassa, June 2019$(N=741)$.
For majority of the respondents reason for unintendedness of the pregnancy was because they were students 76 (77.55\%); 14 (14.29) because they don't have enough money, 4 (4.08) raped and 4 (4.08) not married.

\subsection{Factors Associated with Unintended Pregnancy}

On bivariate analysis collages, year of study, marital status, source of income, decision how to use money and ever use contraceptive were significantly associated with unintended pregnancy. However only, collages, marital status, source of income and ever use contraceptive were remaining statistically significant in multivariate analysis (table 2).

Collage of Agriculture 3.76 times $(\mathrm{AOR}=3.76,95 \% \mathrm{CI}$ : 1.66, 8.50), Social Science and Humanity 2.63 times $(\mathrm{AOR}=$ 2.63, 95\% CI: 1.02, 6.81), and Natural and Computational science 3.41 times $(\mathrm{AOR}=3.76,95 \% \mathrm{CI}: 1.66,8.50)$ were more likely to have unintended pregnancy compared to college of Medicine and Health sciences. Married respondents were $2.39(\mathrm{AOR}=2.39,95 \% \mathrm{CI}: 1.54,7.54)$ times more likely to have unintended pregnancy compared to respondents who were not married. From the respondents $47 \%$ of them whose source of income was parent were $(\mathrm{AOR}=0.53,95 \% \mathrm{CI}: 0.29,0.96)$ less likely to have unintended pregnancy compared to respondents whose source of income were partner. Respondents who used contraceptive were $75 \%(\mathrm{AOR}=0.25,95 \% \mathrm{CI}: 0.14,0.44)$ less likely to have unintended pregnancy compared to who never used (table 2).

Table 2. Associated factors of pregnancy experience among Hawassa University regular female students, Hawassa, June 2019-(N=741).

\begin{tabular}{|c|c|c|c|c|c|}
\hline \multirow{2}{*}{ Variables } & \multirow{2}{*}{ Category } & \multicolumn{2}{|c|}{ Ever pregnant } & \multirow{2}{*}{ COR $(95 \% C I)$} & \multirow{2}{*}{ AOR (95\%CI) } \\
\hline & & Yes N (\%) & No N (\%) & & \\
\hline \multirow{4}{*}{ Colleges } & Agriculture & $32(32.7)$ & $139(21.6)$ & $3.17(1.45,6.91)$ & $3.76(1.66,8.50)^{* *}$ \\
\hline & Social Science and Humanity & $7(7.1)$ & $62(9.6)$ & $1.34(0.55,3.24)$ & $2.63(1.02,6.81)^{*}$ \\
\hline & Natural and Computational Science & $44(44.9)$ & $246(38.3)$ & $2.46(1.16,5.21)$ & $3.41(1.54,7.54)^{* *}$ \\
\hline & Medicine and Health Science & $9(9.2)$ & $124(19.3)$ & 1 & 1 \\
\hline \multirow{2}{*}{ Year } & Year one & $35(35.7)$ & $199(30.9)$ & $1.24(0.79,1.94)$ & $1.25(0.76,2.04)$ \\
\hline & Year two and above & $63(64.3)$ & $444(69.1)$ & 1 & 1 \\
\hline \multirow{2}{*}{ Marital status } & Not married & $83(84.7)$ & $553(86.0)$ & 1 & 1 \\
\hline & Married & $15(15.3)$ & $90(14.0)$ & $1.11(0.61,2.01)$ & $2.39(1.16,4.92)^{*}$ \\
\hline \multirow{2}{*}{ Source of income } & From partner & $27(27.6)$ & $86(13.4)$ & 1 & 1 \\
\hline & From parents & $71(72.4)$ & $554(86.6)$ & $0.41(0.23,0.67)$ & $0.53(0.29,0.96)^{*}$ \\
\hline How to use income & $\mathrm{Me}$ & $68(69.4)$ & $480(74.7)$ & $0.77(0.82,2.06)$ & $1.33(0.77,2.28)$ \\
\hline decided by & Parent/partner/husband & $30(30.6)$ & $163(25.3)$ & 1 & 1 \\
\hline Ever use & Yes & $47(49.5)$ & $145(22.6)$ & $0.03(0.01,0.46)$ & $0.25(0.14,0.44)^{* * *}$ \\
\hline contraceptive & No & $496(77.4)$ & $48(50.5)$ & 1 & 1 \\
\hline
\end{tabular}

Where $*=\mathrm{P}<0.05, * *=\mathrm{P}<0.001, * * *=\mathrm{P}<0.0001$

\section{Discussion}

This study revealed that the magnitude of pregnancy experience among the total respondent was 98 (13.2\%). From this experience of pregnancy none of them were intended. However a study in Medawalabu University shows the overall magnitude of unwanted pregnancy among those who ever had sexual experience been $8.1 \%$ while $1.4 \%$ from total respondents (18). This difference might be due to type of the study area; since Hawassa University locates in the city and potential tourism site with number of night clubs around unlike Medawallabu University.

Moreover, magnitude of unintended pregnancy among pregnant women in Arsi Negele was 32.4\%, (12) and among mothers following antenatal care in Bale Zone was 37.2 (17). This might be due to women's following antenatal care were all pregnant mothers.

In this study Collage of Agriculture, Social Science and Humanity, and Natural and Computational science were more likely to have pregnancy compared to college of Medicine 
and Health science students. This study is supported by studies which states that subjects who have health background have better trend in prevention of unintended pregnancy (28-31). This might be due to relatively health science students have better information on prevention of unintended pregnancy.

In this study married respondents were more likely to have pregnancy compared to respondents who were not married. Unlike studies done in antenatal care unit shows being unmarried was potential exposing factor for unintended pregnancy $(2,3,12,14,28,29,32,33)$. This might be due to respondents who were not married may not have sexual contact in turn they could not have unintended pregnancy.

In this study respondents whose source of income was parent were less likely to have pregnancy compared to respondents whose source of income were partner. Consistently a study in Addis Ababa supports this finding (6). Other studies state that when parents have better income they usually follow, support and control their child's which reduces exposure of unintended pregnancy $(8,10,34-36)$. This might be due to those whose income is from partners might be influenced or forced by their partners due to economic dependency.

In this study respondents who have history of using contraceptive were $75 \%(\mathrm{AOR}=0.25,95 \% \mathrm{CI}: 0.14,0.44)$ less likely to have pregnancy. This result is supported by different studies which state using contraceptive is an absolute preventive mechanism of pregnancy $(3,12,37)$.

\section{Limitation}

Students' might not provide honest answers to the questions; since the study was involved in sensitive issues social desirability bias was inevitable.

\section{Conclusion}

Magnitude of pregnancy experience in which all of them were unintended was high among regular Hawassa University female students compared to other studies. Being non health colleges, married status, partner as a source of income and not using contraceptive were statistically significant factors to have pregnancy.

\section{Recommendations}

1. Non health colleges' needs to be evaluated about their sexual and reproductive health information flow, and the university should monitor appropriateness of information delivery.

2. Qualitative study may need to be employed to identify reason of female students who are economically dependent other than their parents were risky for unintended pregnancy.

3. Married female students need to be emphasized by the university to work with youth family planning services.

4. For students who are sexually active and not using contraceptive needs to be counseled by university integrated with family planning service providers.

\section{Declaration}

\section{Ethical Approval}

Ethical clearance were obtained from Hawassa University College of medicine and health science institutional review board (IRB). Permission obtained from academic vice president and registrar and alumni directorate; oral informed consent was obtained from participants. Confidentiality and anonymity were ensured, and participants were informed that their participation would be voluntary.

\section{Consent for Publication}

Nil

\section{Data Availability}

The data was avilable but can be given with restrictions since individual privacy could be compromised.

\section{Competing of Interest}

The authors declare that we have no competing interests.

\section{Funding}

This research were funded by Hawassa University; but the University have no role on design, collection, analysis, and interpretation of data and in writing the manuscript.

\section{Authors Contribution}

All authors were participated on analysis and manuscript preparation. The conception of the manuscript were by YF.

\section{Acknowledgements}

I have able to plan this work because of my study subjects; your involvement makes this study important, thank you for your participation. Hawassa University takes part in arranging and making favorable condition to conduct this study thank you instead. Families your support makes me to stay strong and work hard be with me always and I love you all.

\section{Abbreviations}

FP: Family Planning

HCA: Hawassa Collage of Agriculture

HU: Hawassa University

IOT: Institute Of Technology

IRB: Institutional Review Board

IUCD: Intra Uterine Contraceptive Device

NGO: Non-Governmental Organization

OR: Odds Ratio

RH: Reproductive health

SNNPR: Southern Nations Nationalities and peoples Region 
SRH: Sexual and Reproductive Health

UP: Unintended Pregnancy

WHO: World Health Organization

\section{References}

[1] Gbagbo FY, Nkrumah J. Family planning among undergraduate university students: a CASE study of a public university in Ghana. BMC women's health. 2019; 19 (1): 12.

[2] Feyisso M, Girma A, Yimam H, Hailu S. Magnitude of Unintended Pregnancy and its Determinants among Pregnant Women Visiting Dilla University Referral Hospital, South Ethiopia. J Women's Health Care. 2017; 6 (388): 21670420.1000388 .

[3] Mulatu T, Cherie A, Negesa L. Prevalence of Unwanted Pregnancy and Associated Factors among Women in Reproductive Age Groups at Selected Health Facilities in Addis Ababa, Ethiopia. J Women's Health Care. 2017; 6 (392): 2167-0420.1000392.

[4] Clutter LB. Experiences of Women With Unintended Pregnancies in Their Twenties Who Chose Open Adoption. Journal of Obstetric, Gynecologic \& Neonatal Nursing. 2017; 46 (3, Supplement): S45-S6.

[5] ICF CSACEa. Ethiopia Demographic and Health Survey. Addis Ababa, Ethiopia, and Rockville, Maryland, USA: CSA and ICF. 2016.

[6] Kassie T, Moges G, Ali A, Tefera W. Magnitude and factors associated with unintended pregnancy among pregnant women in Addis Ababa Ethiopia. Global Journal of Medicine and Public Health. 2017; 6 (4): 15.

[7] Perez M, Baca M, Chambers S, Hettema J, Kosnick S, Moralez-Norris E, et al. 114. The Adapt Study: Development of A Multi-Level Intervention Framework To Reduce Disparities In Unintended Teen Pregnancy Among Hispanic Adolescents. Journal of Adolescent Health. 2019; 64 (2, Supplement): S59-S60.

[8] Moseson H, Dehlendorf C, Gerdts C, Vittinghoff E, Hiatt RA, Barber J. No one to turn to: low social support and the incidence of undesired pregnancy in the United States. Contraception. 2018; 98 (4): 275-80.

[9] Muhindo R, Sanyu B, Nankumbi JO. Factors Associated with Condom Use among University Female Students in Uganda. J Public Health Dis Prev 1: 102 Abstract RESEARCH ARTICLE Open Access. 2018; 1 (1).

[10] Dunn S, Xiong AQ, Nuernberger K, Norman WV. Non-use of Contraception by Canadian Youth Aged 15 to 24: Findings From the 2009-2010 Canadian Community Health Survey. Journal of Obstetrics and Gynaecology Canada. 2019; 41 (1): 29-37.

[11] Tsegaye AT, Mengistu M, Shimeka A. Prevalence of unintended pregnancy and associated factors among married women in west Belessa Woreda, Northwest Ethiopia, 2016. Reproductive health. 2018; 15 (1): 201.

[12] Fite RO, Mohammedamin A, Abebe TW. Unintended pregnancy and associated factors among pregnant women in Arsi Negele Woreda, West Arsi Zone, Ethiopia. BMC research notes. 2018; 11 (1): 671 .
[13] McCarthy M, Upadhyay U, Biggs MA, Anthony R, Holl J, Roberts SCM. Predictors of timing of pregnancy discovery. Contraception. 2018; 97 (4): 303-8.

[14] Getu Melese K, Gebrie MH, Berta Badi M, Fekadu Mersha W. Unintended pregnancy in Ethiopia: community based crosssectional study. Obstetrics and gynecology international. 2016.

[15] Keenan K. Novel methods for capturing variation in unintended pregnancy across time and place. The Lancet Global Health. 2018; 6 (4): e352-e3.

[16] Bearak J, Popinchalk A, Alkema L, Sedgh G. Global, regional, and subregional trends in unintended pregnancy and its outcomes from 1990 to 2014: estimates from a Bayesian hierarchical model. The Lancet Global Health. 2018; 6 (4): e380-e9.

[17] Darega B, Dida N. Unplanned pregnancy: Prevalence and Associated factors among Antenatal Care Attending Women in Bale Zone, Oromiya Region, Southeast Ethiopia: A facilitybased cross sectional study. Global Journal of Medical Research. 2015.

[18] Erena G, Kerbo AA. Unwanted pregnancy and associated factors among female students of Madawalabu University Bale Zone, Oromia Region south east, Ethiopia. Science Journal of Public Health. 2015; 3 (1): 50-5.

[19] Sully E, Dibaba Y, Fetters T, Blades N, Bankole A. Playing it Safe: Legal and Clandestine Abortions Among Adolescents in Ethiopia. Journal of Adolescent Health. 2018; 62 (6): 729-36.

[20] Fekadu Y. Knowledge Attitude and Utilization of Emergency Contraception among Health Science and Medical Students of Arba Minch University, 2015. J Womens Health Care. 2017; 6 (4): $10.4172 / 2167-0420.1000383$.

[21] Liu J, Wu S, Xu J, Temmerman M, Zhang W-H. Repeat abortion in Chinese adolescents: a cross-sectional study in 30 provinces. The Lancet. 2017; 390: S17.

[22] Kumar V, Singh J, Sharma S. Knowledge and Perceptions Regarding Medical Termination of Pregnancy among Medical and Non-medical Students. Prof RK Sharma. 2019; 13 (1): 1.

[23] Come Yelian Adohinzin C, Meda N, Anicet Ouedraogo G, Gaston Belem AM, Sombie I, Berthe A, et al. Knowledge and attitude of young people regarding HIV prevention and unwanted pregnancy in Bobo-Dioulasso, Burkina Faso. Sante publique (Vandoeuvre-les-Nancy, France). 2016; 28 (4): 52534.

[24] Zenebe M, Haukanes H. When abortion is not within reach: Ethiopian university students struggling with unintended pregnancies. International Journal for Equity in Health. 2019; $18(1): 23$.

[25] Geda YF. Determinants of Teenage Pregnancy in Ethiopia: A Case-Control Study, 2019. Curr Med Issues. 2019; 17 (4): 10.4103/cmi.cmi_12_19.

[26] Kassa S, Molla A, Cherie N. Sexual Coercion and Determinant Factors among Female Students in Wollo University, Ethiopia. 2019.

[27] Directorate RbPaIT. A brief overview of Hawassa University: http://wwwhueduet/hu/indexphp/about-hu/overviewhtml 2018. 
[28] Geleto A, Markos J. Awareness of female students attending higher educational institutions toward legalization of safe abortion and associated factors, Harari Region, Eastern Ethiopia: a cross sectional study. Reproductive health. 2015; $12(1): 19$.

[29] Somba MJ, Mbonile M, Obure J, Mahande MJ. Sexual behaviour, contraceptive knowledge and use among female undergraduates' students of Muhimbili and Dar es Salaam Universities, Tanzania: a cross-sectional study. BMC women's health. 2014; 14 (1): 94.

[30] Oyefabi AO, Nmadu AG, Yusuf MS. Prevalence, perceptions, consequences, and determinants of induced abortion among students of the Kaduna State University, Northwestern Nigeria. Journal of Medicine in the Tropics. 2016; 18 (2): 86.

[31] Abera M, Ofori KN, Opito R, Nanfuka M, Mugenyi L, Etukoit $\mathrm{MB}$, et al. Unprotected Sex and Associated Factors among Adolescent Students of Rift Valley University Jimma Campus, Jimma Town, South West Ethiopia: Institution Based Cross Sectional Study. International Journal of HIV/AIDS Prevention, Education and Behavioural Science. 2019; 5 (1): 1.

[32] Yenealem F, Niberet G. Prevalence and associated factors of unintended pregnancy among pregnant woman in Gondar town, North west Ethiopia, 2014. BMC research notes. 2019; 12 (1): 161
[33] Kassahun EA, Zeleke LB, Dessie AA, Gersa BG, Oumer HI, Derseh HA, et al. Factors associated with unintended pregnancy among women attending antenatal care in Maichew Town, Northern Ethiopia, 2017. BMC research notes. 2019; $12(1): 381$.

[34] Getachew FD. Level of Unintended Pregnancy and its Associated Factors among Currently Pregnant Women in Duguna Fango District, Wolaita Zone, Southern Ethiopia. Malaysian Journal of Medical and Biological Research. 2015; 2 (2): $75-88$.

[35] Hall KS, Beauregard JL, Rentmeester ST, Livingston M, Harris KM. Adverse life experiences and risk of unintended pregnancy in adolescence and early adulthood: Implications for toxic stress and reproductive health. SSM - Population Health. 2019; 7: 100344.

[36] Engstrand S, Kopp Kallner H. Cost of unintended pregnancy in Sweden - a possibility to lower costs by increasing LARC usage. Contraception. 2018; 97 (5): 445-50.

[37] Abame DE, Muluembet A, Tesfay A, Yohannes Y, Ermias D, Markos T, et al. Relationship Between Unintended Pregnancy and Antenatal Care Use During Pregnancy in Hadiya Zone, Southern Ethiopia. Journal of Reproduction \& Infertility. 2019; 20 (1): 42-51. 